\title{
Future Solar Irradiance Prediction using Least Square Support Vector Machine
}

\author{
Fahteem Hamamy Anuwar ${ }^{\#}$ and Ahmad Maliki Omar ${ }^{*}$

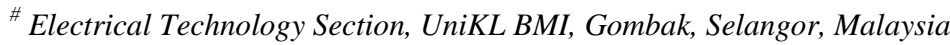 \\ E-mail:fahteem@unikl.edu.my \\ * Green Energy Research Centre, Uitm Shah Alam, Shah Alam, 40150, Selangor, Malaysia \\ E-mail:maliki_omar@salam.edu.my
}

\begin{abstract}
Support vector machine (SVM) based on statistical learning theory has shown its advantage in regression and prediction. This paper presents the future prediction of the solar irradiance using least square support vector machine (LSSVM) which is a kind of SVM with quadric loss function. SVM has greater generalization ability and guarantee global minima for given training data set which will give good performance for solar irradiance with time series prediction. In order to improve the prediction performance of the LSSVM, the experimental data have to be normalized and appropriate parameters are selected by generic algorithm. In this research, solar irradiance data are collected daily at monitoring station located at Green Energy Research Centre (GERC) UiTM, Shah Alam. This related information will be used in prediction of the future data which useful for designing new PV systems and monitoring existing systems performance. The results show good agreement between the predicted against the actual values measured. The proposed solar irradiance time series prediction method is considerable practical value which can be used in other datasets.
\end{abstract}

Keywords - Solar irradiance; support vector machine; least square support vector machine; time series prediction

\section{INTRODUCTION}

Energy is important in all aspects of development to support population growth, urbanization, industrialization as well as tourism industry. Seventy five percent of total global energy demand is supplied by the burning of fossil fuels which contribute to air pollution, global warming concerns, diminishing fossil fuels and increasing costs. Energy consumption is also increasing and several alternative green energy sources are seriously taken into consideration to fulfill energy demand.

The possibility to obtain electrical energy from the sun and to supply electrical energy has been realized due to development of solar panel and power electronic converters. Photovoltaic (PV) technology provides an attractive method of power generation and meets the criteria of clean energy and sustainability [1-3].

Photovoltaic systems are the most promising way to produce clean electricity which directly converts sunlight into electricity easily. Changes in the intensity of the solar irradiance give a major impact to the performance of the PV systems. Fluctuations of the solar irradiance cause troubles between demand and supply and reduce the power quality.
Accurate solar irradiance data is required for modelling and designing of solar energy systems such as photovoltaic, solar thermal and any other applications.

Many research have been carried out related to the estimation of solar energy potential in various locations based on conventional physical models or some statistical assumptions [4-13]. Advanced development in computer technology especially in artificial intelligent techniques have been used for prediction in many engineering areas. Several methods for estimating solar irradiance with artificial intelligent techniques have been done by previous researchers [14-28].

In recent years, Support Vector Machine (SVM) theory was developed by Vapnik [29-30]. There have been an intensive studies on SVM for regression and prediction in which SVM is quite satisfying in theoretical point of view, which leads to a great potential and superior performance in practical applications. The structural risk minimization (SRM) in SVM has been proved superior to the empirical risk minimization (ERM) principle as adopted in neural network. SVM shows powerful generalization ability and guarantee global minima. In addition, SVM is adaptive to complex systems and robust in dealing with corrupted data. Least Square Support Vector Machine (LSSVM) [31-32] 
uses equality constraints instead of inequality constraints and a least squares error term in order to obtain a linear set of equations in the dual space. This unique feature make LSSVM have the advantages of simple structure and high speed. Many great research have been successfully adopted SVM and LSSVM techniques such as fingerprint recognition [33], document categorization [34], traffic pattern recognition [35], forecasting of financial market [36], forecasting of electricity price [37], estimation of power consumption and time series prediction [38].

This research is carried out to investigate the capability of least square support vector machine in forecasting solar irradiance by using the actual measured data obtained from measurement stations. LSSVM model for predicting one day ahead of solar irradiance values by using the real climate data obtained from the monitoring station located at Green Energy Research Centre (GERC) UiTM, Shah Alam. MATLAB was employed for LSSVM applications.

\section{DESCRIPTION OF THE GCPV SYSTEM}

The Grid Connected Photovoltaic (GCPV) power system involved in this research situated in Green Energy Research Center (GERC), University of Technology MARA (UiTM) Shah Alam, Selangor. The system can be described as Table 1. The data of solar irradiance, module temperature, power, voltage and current has been analysed from May 2012 which are recorded every 5 minutes interval using dedicated inbuilt data logger in the individual grid inverter.

TABLE I

GCPV SYSTEM DESCRIPTION

\begin{tabular}{|l|l|}
\hline \multicolumn{1}{|c|}{ Description } & \multicolumn{1}{c|}{ System } \\
\hline Parameters & Monocrystalline \\
$\mathrm{P}_{\mathrm{mp}}(\mathrm{W})$ & 250 \\
$\mathrm{~V}_{\mathrm{mp}}(\mathrm{V})$ & 30.5 \\
$\mathrm{I}_{\mathrm{mp}}(\mathrm{A})$ & 8.2 \\
$\gamma_{\mathrm{gma}}\left(\% \sigma^{-2}\right)$ & -0.42 \\
$\gamma_{\mathrm{m} m \mathrm{~g}}\left(\% \mathrm{C}^{-2}\right)$ & 0.04 \\
$\mathrm{f}_{\text {dirt }}$ & 0.97 \\
$\mathrm{f}_{\text {cable_loss }}$ & 0.98 \\
$\mathrm{f}_{\mathrm{mm}}(\%)$ & 0.95 \\
$\mathrm{f}_{\text {aging }}(\%)$ & 1 \\
\hline Array Configuration & 2 parallel X 20 series \\
\hline Total Capacity & $10 \mathrm{kWp}$ \\
\hline Type of Inverter/ & Sunny Tripower STP8000TL \\
Efficiency $(\%)$ & 98.3 \\
\hline Type of Mounting & Retrofitted on metal deck \\
Structure & \\
\hline
\end{tabular}

\section{LEAST SQUARE SUPPORT VECTOR MACHINES}

LSSVM is an alteration of the standard SVM and was improved by Suykens et al. [39]. LSSVM uses equality constraints instead of inequality constraints and a least squares error term instead of the standard error term.

Giving a training data set of $\mathrm{N}$ samples $\left\{\mathrm{x} \_\mathrm{k}, \mathrm{y} \_\mathrm{k}\right\} \_(\mathrm{k}=1)^{\wedge} \mathrm{Nwith}$ input data $\mathrm{x} \_\mathrm{k} \in \mathrm{R}^{\wedge} \mathrm{n}$ and output data $\mathrm{y}_{\mathrm{k}} \mathrm{k} \in \mathrm{R}$ one considers the following optimization problem in primal weight space:

$$
\min \left\{f(w, \theta)=\frac{1}{2} w^{T} w+\frac{1}{2} y \sum_{k=1}^{N} \theta_{k}^{2}\right\}
$$

Subject to

$$
y_{h}=w^{T} \varphi\left(x_{h i}\right)+b+e_{h i}, \quad k=1 \ldots \ldots N
$$

With $\varphi(s)_{n} \mathbb{R}_{k}$ a function which maps the input space into a higher dimensional feature space, weight vector $w \in R^{n_{k}}$ in primal weight space, error variables $\epsilon_{k} \in R$ and bias term $b$. Note that the cost function $J$ consists of a sum squared error fitting error and a regularization term, which is also a standard procedure for the training of multilayer perceptrons's and is related to ridge regression. The relative importance of these terms is determined by the positive real constant $\gamma$.

In primal weight space one has the model

$$
y(x)=w^{T} p(x)+b
$$

The weight vector $w$ can be infinite dimensional, which makes a calculation of $w$ from (2) impossible in general. Therefore, one computes the model in the dual space instead of the primal space. One defines the Lagrangian

$$
L(w, b, e, a)=J(w, a)-\sum_{k=1}^{N} a_{k}\left\{w^{T}, q\left(x_{k}\right)+b+a_{k}-y_{k}\right\}
$$

With Lagrange multipliers $\alpha_{k} z R$ called support values.

The conditions for optimality are given by

$$
\begin{aligned}
& \frac{\partial L}{\partial w}=0 \rightarrow w=\sum_{k=1}^{N} \alpha_{k i} \varphi\left(x_{k}\right) \\
& \frac{\partial L}{\partial \varepsilon_{k}}=0 \rightarrow \alpha_{k i}=\gamma \theta_{k_{i}} \quad k=1 \ldots \ldots N \\
& \frac{\partial L}{\partial b}=0 \rightarrow \sum_{k=1}^{N} \alpha_{k}=0 \\
& \frac{\partial L}{\partial \alpha_{k}}=0 \rightarrow w^{T} p\left(x_{k}\right)+b+\theta_{k}-y_{k}=0, \quad k=1 \ldots N
\end{aligned}
$$

These conditions are similar to standard SVM optimally conditions, expect for the condition $\sigma_{k}=\gamma \theta_{k}$. At this point one loses the sparseness property in LSSVM.

After elimination of $w, e$ one obtains the solution

$$
\left[\begin{array}{cc}
0 & 1_{v}^{z} \\
1_{y} & \Omega+\frac{1}{y}
\end{array}\right]\left[\frac{b}{a}\right]=\left[\frac{0}{y}\right]
$$

with

$$
y=\left[y_{1} \ldots \ldots y_{N}\right], 1_{v}=[1, \ldots, 1], c=\left[\alpha_{1 m}, \alpha_{N}\right]
$$


and

$$
\Omega_{k l}=\psi\left(x_{k}\right)^{T} \varphi\left(x_{l}\right) \text { for } k, l=1 \ldots \ldots N
$$

According to Mercer's condition, there exists a mapping $\varphi$ and an expansion

$$
K(x, y)=\sum_{i} \varphi_{i}(x) \varphi_{i}(y), \quad x, y \in R^{n}
$$

If and only if, for any $g(x)$ such that $\int g(x)^{2} d x$ is finite, one has

$$
\int K(x, y) g(x) g(y) d x d y \geq 0
$$

As a result, one can choose a kernel $K(.$.$) such$ that $K\left(x_{k}, x_{l}\right)=\varphi\left(x_{k}\right)^{T} \varphi\left(x_{l}\right), \quad k_{2} l=1 \ldots \ldots N$. The resulting LSSVM model for function estimation becomes

$$
y(x)=\sum_{k=1}^{N} \alpha_{k} K\left(x, x_{k}\right)+b
$$

Where $a, b$ is the solution for (8). Chosen different kernel function can build up different LSSVM.

\section{A. LSSVM Model}

The design process of LSSVM predictor, error parameter $y$ called hypermeter and kernel function with its parameter are assigned by user. Parameter $\gamma$ determines the trade-off between margin maximization and training error minimization. Large $y$ give higher penalties to errors and lower generalization. With different kernel function, the predictor will perform differently. This research focused on RBF kernel $K(x, y)=\exp \left(-\frac{\|x-y\|^{2}}{2 \sigma^{2}}\right)$ for solar irradiance prediction.

The parameters included $\sigma$ in RBF function $K(x, y)=\exp \left(-\frac{\|x-y\|^{2}}{2 \sigma^{2}}\right)$ and error parameter $\gamma$ in estimate function.

\section{RESULTS AND DISCUSSION}

This research focused on the one day ahead prediction of solar irradiance. With the time series model and parameters listed above, the solar irradiance predictors built up with LSSVM. According to the theory of LSSVM, model should be built under the training samples. Utilize the 864 groups minutes solar irradiance $(00.00$ a.m. to $11.55 \mathrm{p} . \mathrm{m}$, Jun $1 \mathrm{st}-3 \mathrm{th}$, 2014) as training set and the other 864 groups minutes solar irradiance as testing set to predict solar irradiance values for the next day (Jun 4th,2014). Prediction on the next day followed the same steps with previous day solar irradiance data's. After grid search and cross validate, RBF kernel function was selected as shown in Table 2. Fig 1- Fig.3 shows the final prediction results.

By using the assigned $y, \sigma$ values, the testing of the model is performed. Fig. 1 shows the prediction of solar irradiance for the whole day. From the graph we can see changes in three different periods of time including in the morning, in the noon (maximum sun peak) and the evening. LSSVM predictor can analyze the characteristic of the solar irradiance and accurately forecast the solar irradiance for the next day with $95.43 \%$ of accuracy.

TABLE II

PARAMETERS VALUES IN SOLAR IRRADIANCE PREDICTORS.

\begin{tabular}{|c|c|c|c|}
\hline Parameters & Jun 4 $^{\text {th }}$ & Jun 5 $^{\text {th }}$ & Jun 6 $^{\text {th }}$ \\
\hline$\sigma$ & 21.9453 & 14.5980 & 16.4697 \\
\hline$\gamma$ & 2.0029 & 1.1534 & 6.0540 \\
\hline
\end{tabular}

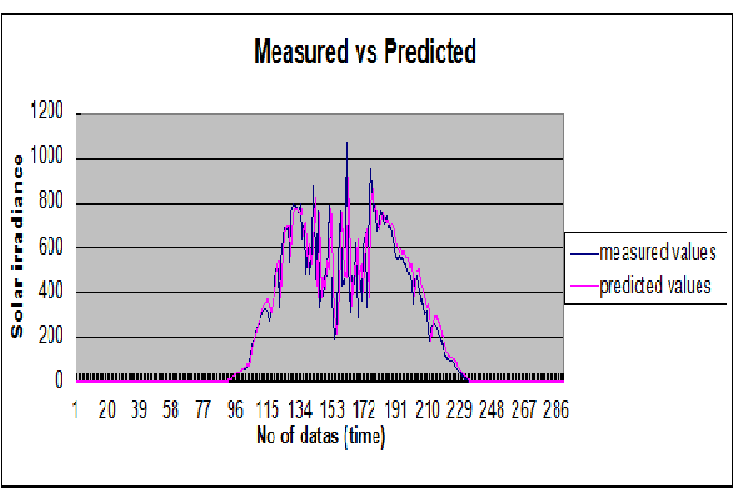

Fig.1. Measured and predicted values (Jun $\left.4^{\text {th }}\right)$

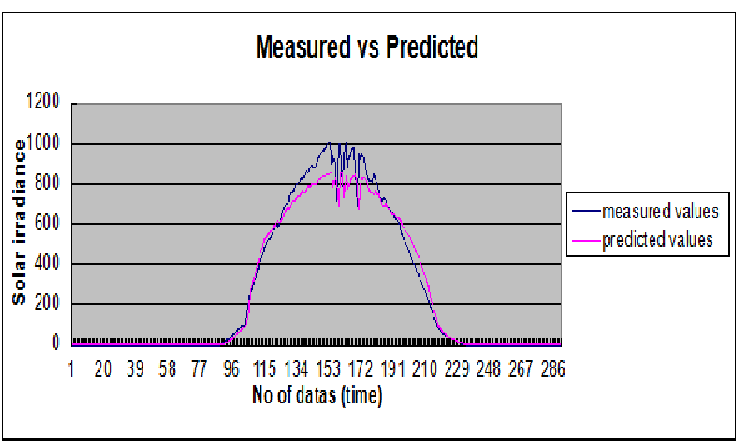

Fig. 2. Measured and predicted values (Jun $5^{\text {th }}$ )



Fig. 3. Measured and predicted values (Jun $6^{\text {th }}$ )

Fig. 2 describes the prediction for Jun $5^{\text {th }}$. We can see that the trend of solar irradiance almost the same from the previous day. LSSVM predictor accurately forecast the solar irradiance with $96.87 \%$ accuracy. In Fig.3 we can see the prediction for the next day based on the previous data. LSSVM predictor successfully forecast the values and gave 97.75\% accuracy. From the results obtained, The LSSVM 
predictor gave the accuracies which can meet engineering practice needs.

\section{CONCLUSIONS}

The performance of the grid connected PV system is majorly influence by the solar irradiance and module temperature. The one day ahead of solar irradiance has been predicted by the LSSVM model. Based on the results, it shows LSSVM accurately estimating solar irradiance values by using the previous measured data as inputs. As solar irradiance change continuously during the day, this prediction will help preventing from the unbalanced electricity production caused by uncertain irradiance conditions.

\section{REFERENCES}

[1] M. Roscia, D. Zaninelli, "Sustainability and Quality through Solar Electric Energy", 10th International Conference on Harmonics and Quality of Power, Vol. 2, pp. $782-787,2002$.

[2] T. Tomita, "Toward Giga-Watt Production of Silicon Photovoltaic Cells, Modules and Systems", 31th IEEE Photovoltaic Specialists Conference, pp. 7 - 11, January 2005.

[3] P. P. Barker, "Advances in Solar Photovoltaic Technology: An Applications Perspective", IEEE Power Engineering Society Summer Meeting, San Francisco, Vol. 2, pp. 1955 - 1960, June 2004.

[4] J.A. Duffie, W.A. Beckman, Solar Engineering of Thermal Processes, second ed., Wiley-Interscience Publication, Canada, 1991.

[5] J.W. Bugler, The determination of hourly insolation on an inclined place using a diffuse irradiance model based on hourly measured global solar radiation, Sol. Energy 19 (1977) 477-491.

[6] C. Gueymard, Mathematically integrable parameterization of clearsky beam and global irradiances and its use in daily irradiation applications, Sol. Energy 50 (1993) 385-397.

[7] J.E. Hay, Calculation of monthly mean solar radiation for horizontal and inclined surfaces, Sol. Energy 23 (1979) 301-307.

[8] T. Muneer, Solar radiation model for Europe, Build. Services Eng. Res. Technol. 11 (1990) 153-163.

[9] O.P. Singh, S.K. Srivastava, A. Gaur, Empirical relationship to estimate global radiation from hours of sunshine, Energy Convers. Manage. 37 (1996) 501-504.

[10] V. Badescu, Correlations to estimate monthly mean daily solar global irradiation: application to Romania, Energy 24 (1999) 883-893.

[11] K. Ulgen, A. Hepbasli, Comparison of solar-radiation correlations for Izmir, Turkey, Int. J. Energy Res. 26 (2002) 413-430.

[12] I. Dincer, S. Dilmac, I.E. Ture, M. Edin, A simple technique for estimating solar-radiation parameters and its application for Gebze, Energy Convers. Manage. 37 (1996) 183-198.

[13] Z. Sen, E. Tan, Simple models of solar radiation data for Northwestern part of Turkey, Energy Convers. Manage. 42 (2001) 587-598.

[14] A. Mellit, A. Massi Pavan, A 24-h forecast of solar irradiance using artificial neural network: application for performance prediction of a grid-connected PV plant at Trieste, Italy, Sol. Energy 84 (2010) 807821.

[15] D.A. Fadare, Modelling of solar energy potential in Nigeria using an artificial neural network model, Appl. Energy 86 (2009) 1410-1422.

[16] F.S. Tymvios, C.P. Jacovides, S.C. Michaelides, C. Scouteli, Comparative study of Ångström's and artificial neural networks' methodologies in estimating global solar radiation, Sol. Energy 7 (2005) 752-762.

[17] Z. Sen, Fuzzy algorithm for estimation of solar radiation from sunshine duration, Sol. Energy 63 (1998) 39-49.
[18] V. Gómez, A. Casanovas, Fuzzy modeling of solar irradiance on inclined surfaces, Sol. Energy 75 (2003) 307-315.

[19] M. Mohandes, S. Rehman, T.O. Halawani, Estimation of global solar radiation using artificial neural networks, Renewable Energy 14 (1998) 179-184.

[20] H.K. Elminir, F.F. Areed, T.S. Elsayed, Estimation of solar radiation components incident on Helwan site using neural networks, Sol. Energy 73 (2005) 270-279.

[21] J. Mubiru, E.J.K.B. Banda, Estimation of monthly average daily global solar irradiation using artificial neural networks, Sol. Energy 82 (2008) 181-187.

[22] O. Senkal, T. Kuleli, Estimation of solar radiation over Turkey using artificial neural network and satellite data, Appl. Energy 86 (2009) 1222-1228.

[23] M.A. Behrang, E. Assareh, A. Ghanbarzadeh, A.R. Noghrehabadi, The potential of different artificial neural network (ANN) techniques in daily global solar radiation modeling based on meteorological data, Sol. Energy 84 (2010) 1468-1480.

[24] A. Mellit, H. Eleuch, M. Benghanem, C. Elaun, A. Massi Pavan, An adaptive model for predicting of global, direct, and diffuse hourly solar irradiance, Energy Convers. Manage. 51 (2010) 771-782.

[25] Cao, X. Lin, Study of hourly and daily solar irradiation forecast using diagonal recurrent wavelet neural networks, Energy Convers. Manage. 49 (2008) 1396-1406.

[26] L. Martin, L.F. Zarzalejo, J. Polo, A. Navarro, R. Marchante, M Cony, Prediction of global solar irradiance based on time series analysis: application to solar thermal power plants energy production planning, Sol. Energy 84 (2010) 1772-1781.

[27] A. Mellit, M. Benghanem, S.A. Kalogirou, An adaptive waveletnetwork model for forecasting daily total solar-radiation, Appl. Energy 83 (2006) 705-722.

[28] C. Paoli, C. Voyant, M. Muselli, M.-L. Nivet, Forecasting of preprocessed daily solar radiation time series using neural networks, Sol. Energy 84 (2010) 2146-2160

[29] V.N.Vapnik, The nature of statistical learning theory. New York: Springer, 1995.

[30] Simon Haykin, Neural networks: A comprehensive foundation, 2nd edition. Pearson Education, NewYork, 1999

[31] Weiwu Yan, Huihe Shao. "Application of support vector machines and least squares support vector machines to heart disease diagnoses", Control and decision, Vol.3, Nov.5, pp.358-360, May 2002.

[32] Suykens J A K, Vandewalle J. "Least squares support vector machine classifiers", Neural Processing Letters, Vol.9, No.3, pp.293-300, Mar.1999.

[33] Shah, Shesha, Sastry, P.S., "Fingerprint classification using a feedback-based line detector", IEEE Trans. On systems, man, and cybernetics, Part B: Cybernetics, Vol.34, pp.85-94, 2004.

[34] Leopold, Edda, Kiindermann, Jorge, "Text categorization with support vector machines: How to represent texts in input space", Machine Learning, Vol.46, pp.423-444, 2002

[35] Lee, K.L., Billings, S.A., "Time series prediction using support vector machines, the orthogonal and the regularized orthogonal leastsquares algorithms", International Journal of systems science, Vol.33, pp.811-821, 2002.

[36] H.Yang, L. Chan, and I.King, "Support vector machine regression for volatile stock market prediction", In Proc. Intelligent data engineering and automated learning, Springer LNCS2412, pp.391396, 2002.

[37] D.C. Sansom, T. Downs, and T.K. Saha, "Evaluation of support vector machine based forecasting tool in electricity price forecasting for Australian National Electricity Market participants", J. Elect. Electron. Vol. 22, pp227-234, 2002.

[38] A.Ding, X.Zhao, and L.Jiao, "Traffic flow time series prediction based on statistics learning theory" Proceedings of IEEE 5th Int. Conf. Intelligent,Transportation Systems, Singapore, pp.727-730, Sep.2002.

[39] J.A.K. Suykens, T. van Gestel, J. de Brabanter, B. de Moora, J. Vandewalle, Least-Squares Support Vector Machines, World Scientifics, Singapore, 2002. 